\title{
Does the addition of dextrose to IV crystalloid therapy provide clinical benefit in acute dehydration? A systematic review and meta-analysis
}

\author{
Ashley Grigsby, DO*†; Jennifer Herron, MLIS ${ }^{\ddagger}$; Benton R. Hunter, MD ${ }^{\dagger}$
}

\begin{abstract}
CLINICIAN'S CAPSULE
What is known about the topic?

Intravenous dextrose halts endogenous ketone production and is commonly recommended in dehydrated patients unable to tolerate oral intake.

What did this study ask?

Is there evidence that the addition of dextrose to intravenous fluids provides a clinically meaningful benefit in dehydrated patients?

What did this study find?

Intravenous dextrose has not been shown to provide any important benefit to patients in this setting, but further research is needed.

Why does this study matter to clinicians?

In dehydrated patients, clinicians should not feel obligated towards dextrose containing solutions, which may be more expensive and less readily available.
\end{abstract}

\section{ABSTRACT}

Objectives: Intravenous dextrose aids in the resolution of ketosis in dehydrated patients not tolerating oral glucose and is often recommended in this clinical scenario. Our aim was to determine whether the addition of dextrose to intravenous rehydration solutions results in decreased hospital admissions or other clinically important benefits among dehydrated children or adults.

Methods: MEDLINE, EMBASE, Web of Science, SCOPUS, and the Cochrane Library were searched by a medical librarian from inception through November 2017. The inclusion criteria were randomized controlled trials comparing dextrose containing intravenous solutions with intravenous solutions without dextrose in patients being treated for dehydration, and not already hospitalized.
Results: The database and bibliographies search identified 1,472 unique citations. Only two trials $(N=333)$ met the inclusion criteria. Both compared normal saline with solutions of dextrose in normal saline. There was no statistically significant difference in admission rates (relative risk $=0.83$; $95 \%$ confidence interval $=0.62$ to 1.10 ) or revisits (relative risk $=0.54$; $95 \%$ confidence interval $=0.24$ to 1.22 ). Heterogeneity was low $\left(\mathrm{I}^{2}=0\right)$. No other outcome results were eligible for pooling, but neither study found differences in any clinical outcomes. No adverse events were reported in either trial.

Conclusions: The addition of dextrose to intravenous saline has not been shown to improve clinical outcomes in dehydrated children presenting to the emergency department with gastroenteritis, but the confidence intervals around the estimate of effect are wide and include the possibility of substantial benefit.

\section{RÉSUMÉ}

Objectif: Les perfusions de dextrose aident à neutraliser la cétose chez les patients en état de déshydratation qui ne tolèrent pas la prise orale de glucose, et le traitement est souvent recommandé dans ces situations cliniques. L'étude visait donc à déterminer si l'adjonction de dextrose aux solutions de réhydratation intraveineuse se traduisait par une réduction du nombre d'hospitalisations ou offrait d'autres avantages cliniques importants chez les enfants et les adultes.

Méthode: Une recherche a été menée dans les bases de données MEDLINE, EMBASE, SCOPUS, la plateforme Web of Science et la bibliothèque Cochrane Library par un bibliothécaire spécialisé dans le domaine médical, depuis leur mise sur pied jusqu'à novembre 2017. Les critères de sélection consistaient en la recherche d'essais à répartition aléatoire, dans lesquels étaient comparées des solutions de perfusion additionnées de dextrose à celles n'en contenant pas chez les patients externes, traités pour de la déshydratation.

From the *Department of Pediatrics, Indiana University School of Medicine, Indianapolis, IN; †Department of Emergency Medicine, Indiana University School of Medicine, Indianapolis, IN; and the $¥$ Ruth Lilly Medical Library, Indiana University School of Medicine, Indianapolis, IN.

Correspondence to: Dr. Benton R. Hunter, Indiana University School of Medicine, Department of Emergency Medicine, 1701 N. Senate Ave., Indianapolis, IN 46202; Email: brhunter@iu.edu

(C) Canadian Association of Emergency Physicians 
Résultats: La recherche documentaire dans les bibliographies et les bases de données a permis de relever 1472 citations uniques; toutefois, 2 essais $(n=333$ ) seulement satisfaisaient aux critères de sélection. Dans les deux cas, on comparait des solutions physiologiques salées à des solutions physiologiques salées additionnées de dextrose. II n'est ressorti aucun écart significatif en ce qui concerne le taux d'hospitalisation (taux relatif $[\mathrm{TR}]=0,83$; intervalle de confiance $[\mathrm{IC}]$ à $95 \%=$ $0,62-1,10)$ ou de reconsultation (TR=0,54; IC à $95 \%=$ $0,24-1,22)$. Quant à I'hétérogénéité, elle était faible $\left(I^{2}=0\right)$. Aucun autre résultat ne se prêtait à une mise en commun, mais il ne s'est pas dégagé non plus de différence entre les deux études à l'égard de quelque résultat clinique que ce soit. Enfin, aucun événement indésirable n'a été signalé dans I'un ou l'autre des essais.

Conclusion: L'adjonction de dextrose aux solutions physiologiques salées ne s'est pas traduite par une amélioration des résultats cliniques chez les enfants en état de déshydratation, traités au service des urgences pour une gastroentérite; toutefois, les intervalles de confiance entourant l'estimation des effets sont larges et pourraient comporter des avantages importants.

Keywords: dehydration, dextrose, intravenous fluids

\section{INTRODUCTION}

Vomiting, diarrhea, and dehydration are common reasons for emergency department (ED) visits and hospitalizations, especially in pediatric patients. ${ }^{1-3}$ Dehydration is often secondary to gastrointestinal losses but can occur from renal dysfunction, skin losses such as sweat and burns, and third space sequestration. ${ }^{4,5}$ Gastroenteritis accounts for 10 percent of pediatric admissions and approximately 300 deaths in children under age 5 in the United States annually, with a similar disease burden in Europe. ${ }^{2,6}$ Oral rehydration is widely recommended for mild to moderate dehydration. ${ }^{7,8}$ However, some patients are unable to tolerate oral rehydration, and IV crystalloid is frequently used..$^{8-11}$

Ketosis may complicate dehydration when illness prevents the intake of adequate carbohydrates, leading to increased free fatty acid breakdown and ketogenesis. ${ }^{5,12}$ Ketoacidosis occurs when there is no carbohydrate substrate and thus no insulin secretion, triggering lipolysis and ketogenesis to prevent hypoglycemia. ${ }^{13}$ Patients with lower serum bicarbonate levels are less likely to tolerate oral fluids, ${ }^{5,14}$ leading to the belief that acidosis contributes to failure of oral rehydration. Because the administration of carbohydrate substrate limits fatty acid oxidation and ketone production, IV glucose should encourage the resolution of ketosis and acidosis, hastening the tolerance of oral intake and speeding recovery. ${ }^{5,15}$

Children are at increased risk for dehydration ${ }^{5}$ and ketosis, due to higher brain energy requirements and lower glycogen stores to produce glucose in times of decreased carbohydrate intake. ${ }^{13}$ Acute dehydration thus leads to ketonemia sooner in children than adults (1 day v. 3 days). ${ }^{13,16}$ These pathophysiologic features suggest that pediatric patients with dehydration, particularly from vomiting and diarrhea, should be most likely to benefit from IV dextrose.

The objective of this review was to determine whether existing evidence from randomized controlled trials (RCTs) supports the common teaching that the addition of dextrose to IV rehydration solution improves clinical outcomes in dehydrated patients not already admitted to the hospital. We planned a subgroup analysis to determine whether the evidence supports a larger effect size in children than adults.

\section{METHODS}

This systematic review follows the PRISMA guidelines for performing and reporting systematic reviews.

\section{Search strategy}

MEDLINE (OvidSP and PubMed interfaces), EMBASE, Web of Science, SCOPUS, and the Cochrane Library were searched by a medical librarian through November 10, 2017. MeSH terms included: Glucose; Administration, Intravenous; Infusions, Intravenous; Dehydration; and Water-Electrolyte Balance. Keywords included variations of these terms and truncations to retrieve any possible alternative use of the terms. Full strategies are available in the appendix. No date or language restrictions were applied. Experts in the field were queried to identify additional trials. Titles and abstracts identified by the search were screened independently by two authors, and the full text was retrieved if either author felt the study was potentially eligible. Full 
text retrievals were reviewed independently by both authors to determine final eligibility for inclusion in the systematic review, with disagreements settled by discussion or adjudicated by the third author. The bibliographies of retrieved articles and related reviews were searched for additional studies. Lastly, a search was run on trial registries (e.g., ClinicalTrials.gov) to identify missed, ongoing, or unpublished trials.

\section{Inclusion-exclusion criteria}

Studies included were randomized, quasi-randomized, or cluster randomized trials comparing an IV solution containing dextrose at any concentration to an IV solution containing no dextrose in non-admitted (ED or outpatient clinic) patients with dehydration. Patients with a source of fluid losses or decreased intake and a need for rehydration therapy, in the opinion of the treating provider, were counted as dehydrated. This definition reflects how dehydration is clinically diagnosed in outpatient settings where accurate baseline body weight is usually unknown. Predefined exclusion criteria were studies of patients already admitted, those with known diabetes, hypoglycemia, underlying metabolic disorders, or known severe metabolic derangements, and patients with hemodynamic instability. Also excluded were studies of surgical patients. We chose to exclude inpatients because the intention of this review was to focus on the initial resuscitation of dehydrated patients. For similar reasons, we sought studies evaluating bolus infusions and excluded trials of maintenance or supra-maintenance intravenous infusions.

\section{Data abstraction}

Two authors independently abstracted data from each included study using standardized data abstraction forms. Abstracted information included intervention and control solutions, inclusion and exclusion criteria, setting, year and duration of study, and number of patients in the intervention and control groups meeting each of our predefined end points, if available. Any discrepancies were to be resolved by discussion and a re-evaluation of the original manuscript.

\section{Quality appraisal of included studies}

Two authors independently assessed the risk of bias (RoB) of included studies using the Cochrane RoB tool, a validated quality assessment tool for randomized trials. ${ }^{17}$ Discrepancies regarding RoB designation of any aspects of included studies were resolved by discussion. Colour-coded tables depicting RoB for each domain of the included studies were created using RevMan 5.3.

\section{Outcomes}

The predefined primary outcome was hospital admission during the index visit, an objective and patient-important measure of immediate treatment failure in outpatients. Several secondary clinical outcomes were identified a priori and included in the data abstraction, including 1) length of stay in the ED or clinic, 2) return visits within 1 week to the ED or necessitating IV therapy, 3) admission to the hospital within 1 week, 4) a change in dehydration scores, and 5) a patient or surrogate reported change in symptom burden.

Adverse events identified a priori and abstracted included hyperglycemia (defined as blood glucose $>200 \mathrm{mg} / \mathrm{dL}$ ), symptomatic hypoglycemia (blood glucose $<70$ with any symptoms), seizure, sepsis diagnosis within 1 week, and mortality.

\section{Statistical analysis}

Meta-analyses were performed using RevMan 5.3. Binary outcomes were meta-analysed using the MantelHaenszel method, under a fixed-effects assumption if heterogeneity was low $\left(I^{2}<25\right)$, or random effects if heterogeneity was moderate or high $\left(I^{2} \geq 25\right.$, or significant clinical heterogeneity). Results of binary outcomes are reported as relative risk (RR) with $95 \%$ confidence intervals (CI). Comparisons of continuous variables were to be reported as the mean difference with $95 \% \mathrm{CI}$ and calculated using the inverse variance method. We planned three subgroup analyses: pediatric patients (age $<18$ years); pregnant women of any age; and nonpregnant adults (age $\geq 18$ years).

\section{RESULTS}

Figure 1 demonstrates the flow of study identification. The literature search identified 1,472 citations. After a review of titles and abstracts, 24 studies were retrieved for full text review. Reasons for exclusion are shown in Figure 1. Only two trials met our inclusion and exclusion 


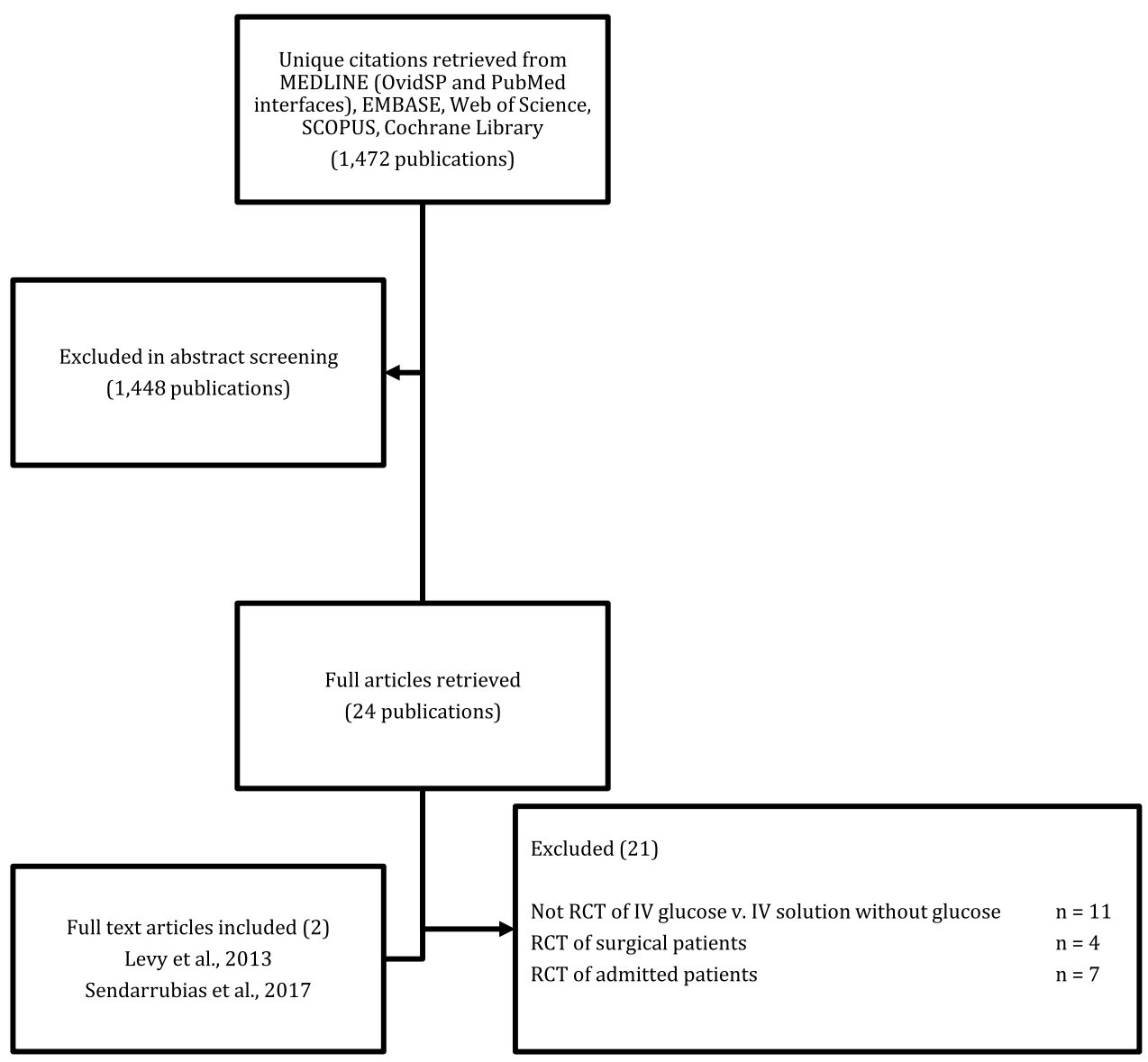

Figure 1. Literature search results.

criteria. Hand searching bibliographies of full text retrievals and related reviews did not identify any additional trials. Two unpublished trials (NCT01285713; NCT02054585) were identified on ClinicalTrials.gov. There were no disagreements regarding study inclusion.

\section{Study characteristics and RoB}

The two included trials ${ }^{18,19}$ were similar in size and the demographics of enrolled patients. Both trials were performed in the ED and enrolled healthy children with acute gastroenteritis needing IV rehydration as determined by the treating clinician. The average age in each trial was 2-3 years, all patients were diagnosed with gastroenteritis, and children with chronic illness were excluded. The average Gorelick dehydration score was 3-4, which indicates $5 \%-9 \%$ loss of body weight. ${ }^{20}$ The control solution in both studies was $0.9 \%$ saline (NS). The intervention group in Levy et al. ${ }^{18}$ received $5 \%$ dextrose in NS (D5NS), whereas
Sendarrubias et al. ${ }^{19}$ used $2.5 \%$ dextrose in NS (SGNS). Each trial gave a $20 \mathrm{~mL} / \mathrm{kg}$ bolus of study fluid, with further hydration determined by the treating clinician. The primary outcome in both RCTs appeared to be need for hospitalization, though no outcome was specified as primary by Sendarrubias et al. ${ }^{19}$ Both studies also reported return visits, change in dehydration scores, and laboratory end points. Further characteristics of each study, including specific inclusion and exclusion criteria, can be found in Table 1.

Although patients and interventions were very similar between studies, the RoB of the two trials was discrepant, with Levy et al. ${ }^{18}$ at generally low RoB and Sendarrubias et al. ${ }^{19}$ at high RoB. Details are summarized in Table 2. Both trials were deemed unclear RoB for selective reporting because adverse events were not defined a priori. Levy et al. ${ }^{18}$ was also at unclear risk of "other bias" for baseline differences between the treatment arms favouring the D5NS group, and because $55 \%$ of the patients randomized to control (NS) received IV 
Ashley Grigsby et al.

\begin{tabular}{|c|c|c|c|c|c|c|}
\hline Study & Setting & Population & Exclusion criteria & Intervention & Control & Outcomes \\
\hline $\begin{array}{l}\text { Levy et al., } \\
2013\end{array}$ & ED & $\begin{array}{l}188 \text { patients ages } 6 \\
\text { months to } 6 \text { years } \\
\text { (median age } 2-2.4 \text { years, } \\
\text { IQR } 1.1-3.9 \text { years), } \\
\text { getting IV hydration for } \\
\text { AGE }\end{array}$ & $\begin{array}{l}\text { Chronic illness; disorder of } \\
\text { glucose metabolism; >7 } \\
\text { days symptoms; IVF in last } \\
12 \mathrm{hr} \text {; suspected } \\
\text { comorbidity }\end{array}$ & $\begin{array}{c}\text { Dextrose } 5 \% \text { in } \\
0.9 \% \text { saline }\end{array}$ & $\begin{array}{l}\text { Saline } \\
0.9 \%\end{array}$ & $\begin{array}{l}\text { Admission; unscheduled } \\
\text { medical care } 48-72 \mathrm{hr} ; \\
\text { change in serum ketones } \\
\text { at } 2 \mathrm{hr} \text {; length of stay; } \\
\text { change in general } \\
\text { appearance score at } 3 \mathrm{hr}\end{array}$ \\
\hline $\begin{array}{r}\text { Sendarrubias } \\
\text { et al., } 2017\end{array}$ & ED & $\begin{array}{l}145 \text { patients ages } 6 \\
\text { months to } 16 \text { years } \\
\text { (median age } 2-3 \text { years, } \\
\text { IQR 1-5 years) with AGE } \\
\text { and moderate to severe } \\
\text { dehydration or failed oral } \\
\text { hydration }\end{array}$ & $\begin{array}{l}>35 \mathrm{~kg} \text {; hemodynamic } \\
\text { instability; chronic } \\
\text { underlying disease; blood } \\
\text { glucose < } 50 \mathrm{mg} / \mathrm{dL} ; \\
\text { serum sodium } \\
\quad<125 \mathrm{mmol} / \mathrm{L} ;>5 \text { days } \\
\text { symptoms }\end{array}$ & $\begin{array}{l}\text { Serum glucose } \\
2.5 \% \text { in } \\
0.9 \% \text { saline }\end{array}$ & $\begin{array}{l}\text { Saline } \\
0.9 \%\end{array}$ & $\begin{array}{l}\text { Admission; return to ED } 7 \\
\text { days; change in Gorelick } \\
\text { dehydration score at } 2 \mathrm{hr} ; \\
\text { variation in blood glucose } \\
\text { and ketone levels }\end{array}$ \\
\hline
\end{tabular}

dextrose after the initial bolus, which could bias the results towards null. The study was low RoB in all other domains.

The study by Sendarrubias et al. ${ }^{19}$ was an open label trial with unclear methods for randomization and allocation concealment. Other RoB was also rated as high

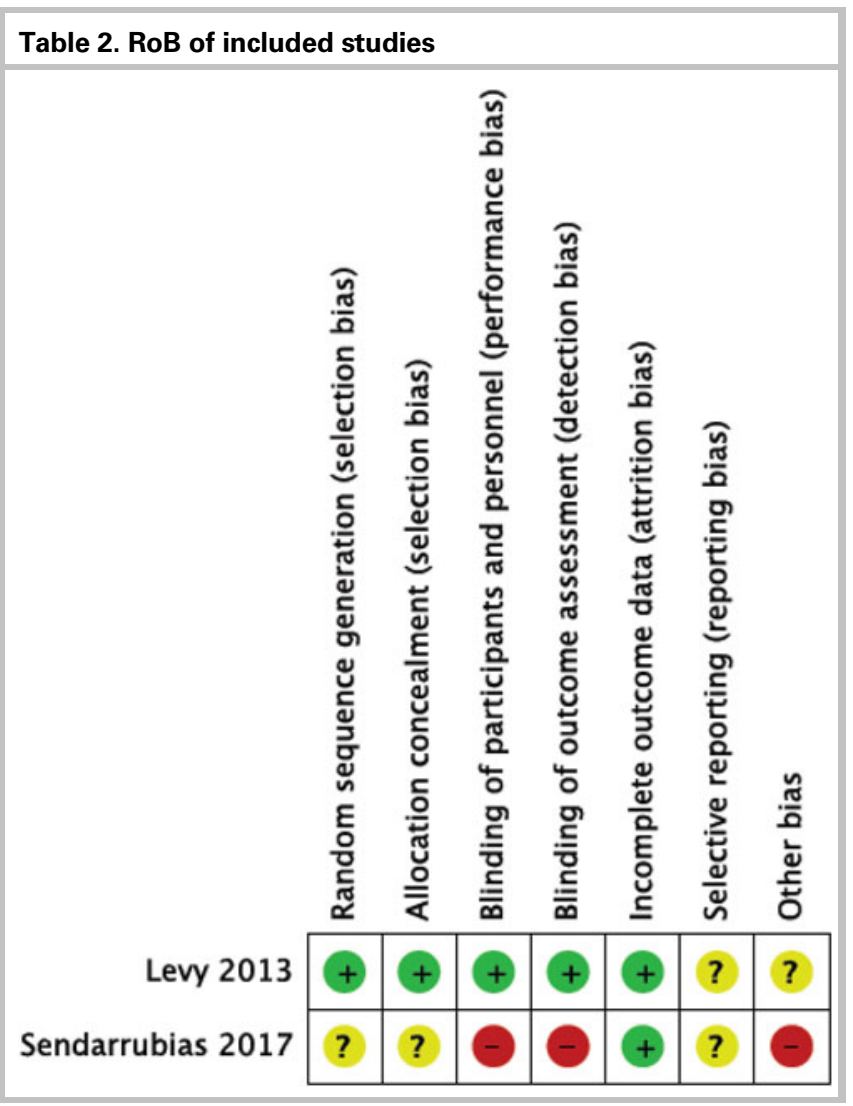

because the study was stopped early after an interim analysis revealed a much lower than expected between-group difference in hospital admissions. The investigators decided to stop the trial after enrolling 145 of a planned 718 children, to propose a larger multicentre study.

\section{Clinical results}

Both studies ${ }^{18,19}$ reported on the primary outcome, and these results were pooled $(\mathrm{N}=333)$. Dextrose containing IV fluid for dehydration did not result in a statistically significant decrease in hospitalization at the index visit when compared with NS (RR 0.83; 95\% CI 0.62 to 1.10). These results are summarized in Figure 2. Heterogeneity was low $\left(I^{2}=0\right)$, and the results were unchanged when analysed using a random effects model.

Both studies reported on the need for further medical care but used different outcomes. Levy et al. ${ }^{18}$ used telephone follow-up at 48-72 hours after ED discharge to assess for unscheduled medical care sought for vomiting or refusal to drink in that timeframe $(n=100)$, with $12 \%$ lost to follow-up. Sendarrubias et al. ${ }^{19}$ reported on return ED visits among those discharged from the index visit $(\mathrm{n}=101)$. The reason for the return visit was not recorded, and the methods do not describe how this information was obtained. A meta-analysis of these results is displayed in Figure 3 and did not result in a statistical difference in need for additional medical care after discharge (RR 0.54; 95\% CI 0.24 to 1.22 ).

Both studies reported on changes in dehydration scores but used different scales. Levy et al. ${ }^{18}$ found no 


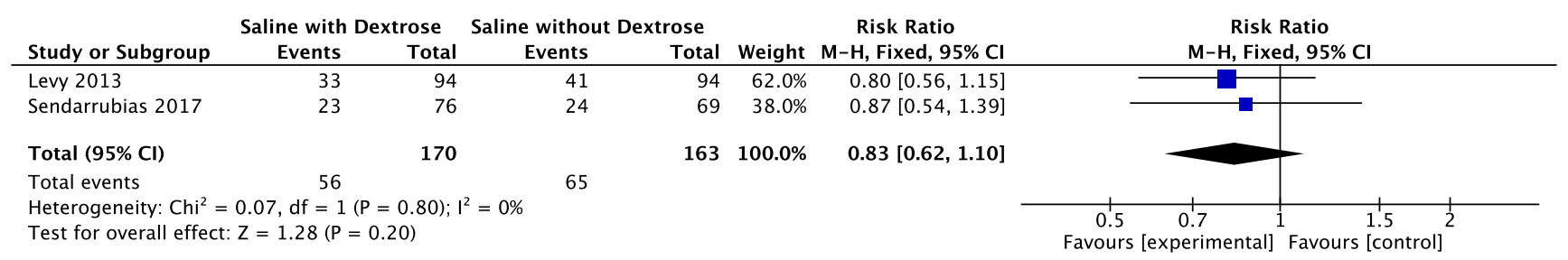

Figure 2. Effect on Hospital Admission

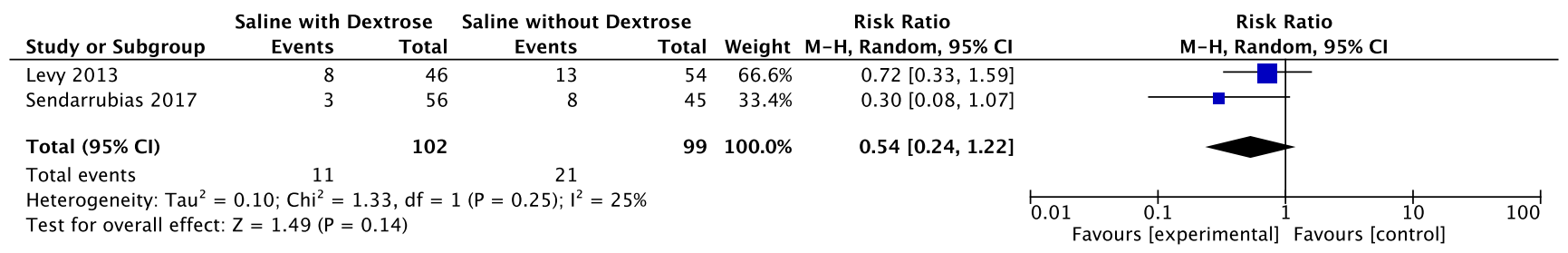

Figure 3. Effect on Revisits

difference in improvement on a "general appearance score" from 1-5. On average, children in both arms of the study improved by 1 point at 3 hours. Sendarrubias et al. ${ }^{19}$ reported that there was no difference in the change in Gorelick dehydration score between study groups, with children in both arms of the trial improving by 2 points on average after 2 hours. These results could not be pooled. Length of ED stay was reported only in Levy et al., ${ }^{18}$ who found no difference between those randomized to D5NS (280 minutes) versus those randomized to NS (288 minutes). None of the other predefined clinical outcomes of this review were reported in either study. Both studies reported that there were no adverse events, but these were not well defined in either trial.

\section{Laboratory results}

No cases of symptomatic hypoglycemia were reported, and Sendarrubias et al. ${ }^{19}$ states that "hypoglycemia was not reported" at all. Levy et al. ${ }^{18}$ found that hypoglycemia (blood sugar $<60 \mathrm{mg} / \mathrm{dL}$ ) was more common in the NS group at 1 hour, but by 2 hours there was no difference, with three patients in each group who were hypoglycemic. None were reported to be symptomatic.

Hyperglycemia (blood sugar > $200 \mathrm{mg} / \mathrm{dL}$ ) was reported in four SGNS patients and 0 NS patients by Sendarrubias et al., ${ }^{19}$ with the timeframe not specified. Levy et al. ${ }^{18}$ did not report hyperglycemic events, but the median blood glucose in the intervention arm at 1 hour was $272 \mathrm{mg} / \mathrm{dL}$ (interquartile range $[\mathrm{IQR}]=221-361$ ).
By 2 hours, this had decreased to $154(\mathrm{IQR}=121-221)$. No cases were reported to be symptomatic.

Both studies reported change in serum ketones as a secondary outcome. In both trials, dextrose containing fluid resulted in significantly more rapid clearance of serum ketones. Sendarrubias et al. ${ }^{19}$ found that serum ketones had decreased significantly more at 2 hours in SGNS treated patients than in NS treated controls $(p<0.001)$. By 4 hours, the difference had diminished and was no longer statistically significantly different $(p=0.08)$. Levy et al. ${ }^{18}$ found that D5NS-treated patients had a larger decrease in ketonemia at 2 hours (mean difference $1.6 \mathrm{mmol} / \mathrm{L}$; $95 \%$ CI 0.9 to $2.3 \mathrm{mmol} / \mathrm{L}$ ).

\section{DISCUSSION}

This systematic review found that current evidence does not support the addition of dextrose to IV solutions to improve clinical outcomes in healthy dehydrated children with acute gastroenteritis. Due to the limitations of the available evidence, however, no firm recommendations can be made for or against its use. Confidence in the effect estimate of our primary outcome is low and was downgraded for imprecision and RoB. For the outcome of repeat visits, confidence is very low and was downgraded for imprecision, high RoB, and clinical heterogeneity. We suggest that, pending the results of ongoing trials, the use of IV rehydration with or without dextrose is reasonable in this setting.

The two included trials ${ }^{18,19}$ were performed in the patient group most likely to benefit according to 
pathophysiology (vomiting children) and did confirm that ketone clearance was faster in dextrose-treated patients. Why this did not result in a clinical benefit is uncertain. It is possible that the improved ketone clearance is too brief to make a clinical impact. This theory is supported by the finding that there was no longer any difference in ketone clearance by 4 hours. ${ }^{19}$ It is also possible that ketone clearance rate is wholly unimportant, or that the meta-analysis was underpowered to find clinical differences.

Although our review included only two trials, ${ }^{18,19}$ additional data from RCTs do exist. Seven RCTs have evaluated IV glucose in admitted nonsurgical patients. ${ }^{21-27}$ While none of these trials suggested any clinical benefit with dextrose solutions, most did not report specifics of clinical outcomes. Five of these trials enrolled severely dehydrated children with presumed cholera diarrhea. ${ }^{22-26}$ All five reported that time to rehydration was similar between groups, but only one trial ${ }^{23}$ gave specific numbers (2.3 v. 2.4 hours). All five studies reported that all patients made a complete recovery. In a very different patient population, Akech et al. ${ }^{21}$ found no difference in outcomes between Ringer's lactate (RL) or half strength Darrow's solution with 5\% dextrose (HSD/D5) among malnourished Kenyan children with shock mostly due to diarrhea (mortality 58\% HSD/ D5 v. $45 \%$ RL $[p=0.42])$. Tan et al. ${ }^{27}$ performed the only trial in any adult population, enrolling 202 patients admitted for hyperemesis gravidarum, and found that D5NS produced similar clinical results to NS. While these inpatient RCTs included almost no quantitative results and were not included in the review, they all support our findings of no benefit with the addition of dextrose.

Our trial registries search identified two additional studies that appear to meet the inclusion and exclusion criteria of this review. One of these (ClinicalTrials.gov NCT01285713) is a small trial that randomized 83 children with gastroenteritis to either NS or D5NS and completed enrolment in 2012. The authors confirmed that the trial has been completed but is not yet published. Although specific results were not available, sensitivity analyses, including the plausible range of results based on information shared by the authors, found that it is very unlikely that its inclusion would change the conclusions of our review. The second trial (ClinicalTrials.gov NCT02054585) is a large multicentre study that plans to randomize 700 children with dehydration and vomiting to either D5NS or NS. It is scheduled for completion in 2019 and should add substantially to what is known about the utility of dextrose in IV rehydration in children.

\section{Limitations}

The main limitation of this review is the paucity of data meeting the inclusion criteria. The CIs around the estimate of effect are thus quite wide and include the possibility that dextrose-containing fluids provide a substantial clinical benefit that our analysis was underpowered to detect.

One of the included trials, ${ }^{19}$ representing almost half of the total patients in the review, was at high RoB. In addition to being an open label study, it was stopped early for futility. It is unclear what effect this may have had on the results, but the effect size of this trial was very similar to that seen in the lower RoB study. ${ }^{18}$

We chose hospital admission as our primary outcome because it is patient-important, easy to measure, and in acute dehydration, usually reflective of the response to treatment. However, it is not an entirely objective outcome. Factors other than response to rehydration therapy may play a role in the decision to admit or discharge. Social issues, patient or caregiver comfort, access to follow-up care, and financial considerations can all impact the disposition decision, and these considerations may play an even larger role in the decisionmaking process when dealing with pediatric patients. It is possible that unmeasured imbalances of these factors impacted the results.

We had planned to pool results for multiple clinical outcomes, but many were not reported in one or both of the included studies. Subgroup analyses also could not be performed. All included patients were children with gastroenteritis, and the included studies did not provide information to assess the effect in severe versus mild or moderate dehydration.

There is potential for publication bias. Although we could not assess for publication bias using a funnel plot with only two published studies, we did identify one small, unpublished trial that was completed several years ago. Our search of trial registries did not identify other completed and unpublished trials, but more could exist.

Finally, included studies used different concentrations of dextrose (5\% v. $2.5 \%)$ in NS as their intervention. These two concentrations of dextrose could perform differently in this clinical scenario. 


\section{CONCLUSION}

The addition of dextrose to IV rehydration solution has not been shown to decrease hospital admissions, repeat visits for medical care, or result in any clinical benefit among pediatric outpatients with acute dehydration. However, this conclusion is based on two small RCTs at moderate to high RoB, resulting in CIs surrounding the estimate of effect that are wide and include the possibility for substantial benefit. At least one larger trial is underway. No randomized studies in adult outpatients were identified.

\section{SUPPLEMENTARY MATERIAL}

The supplementary material for this article can be found at https://doi.org/10.1017/cem.2018.500.

Competing interests: None declared.

\section{REFERENCES}

1. Gindi RM, Jones LI. Reasons for emergency room use among U.S. children: National Health Interview Survey, 2012. NCHS Data Brief 2014(160):1-8.

2. National Collaborating Centre for Women's and Children's Health. National Institute for Health and Clinical Excellence: guidance. Diarrhoea and vomiting caused by gastroenteritis: diagnosis, assessment and management in children younger than 5 years. London: RCOG Press National Collaborating Centre for Women's and Children's Health; 2009.

3. Schappert SM, Burt CW. Ambulatory care visits to physician offices, hospital outpatient departments, and emergency departments: United States, 2001-02. Vital Health Stat 13 2006(159):1-66.

4. Better OS. Impaired fluid and electrolyte balance in hot climates. Kidney Int Suppl 1987;21:S97-101.

5. Reid SR, Losek JD. Rehydration: role for early use of intravenous dextrose. Pediatr Emerg Care 2009;25(1):49-52, quiz $3-4$.

6. Elliott EJ. Acute gastroenteritis in children. BMF 2007;334 (7583):35-40.

7 . Farthing M, Salam MA, Lindberg G, et al.: Acute diarrhea in adults and children: a global perspective. 7 Clin Gastroenterol 2013;47(1):12-20.

8. King CK, Glass R, Bresee JS, Duggan C. Managing acute gastroenteritis among children: oral rehydration, maintenance, and nutritional therapy. MMWR Recomm Rep 2003;52 (Rr-16):1-16.

9. Conners GP, Barker WH, Mushlin AI, Goepp JG. Oral versus intravenous: rehydration preferences of pediatric emergency medicine fellowship directors. Pediatr Emerg Care 2000;16(5):335-8.
10. Reid SR, Bonadio WA. Outpatient rapid intravenous rehydration to correct dehydration and resolve vomiting in children with acute gastroenteritis. Ann Emerg Med 1996;28 (3):318-23.

11. Simpson JN, Teach SJ. Pediatric rapid fluid resuscitation. Curr Opin Pediatr 2011;23(3):286-92.

12. Levy JA, Bachur RG. Intravenous dextrose during outpatient rehydration in pediatric gastroenteritis. Acad Emerg Med 2007;14(4):324-30.

13. Toth HL, Greenbaum LA. Severe acidosis caused by starvation and stress. Am 7 Kidney Dis 2003;42(5):E16-9.

14. Colletti JE, Brown KM, Sharieff GQ, et al. The management of children with gastroenteritis and dehydration in the emergency department. 7 Emerg Med 2010;38(5):686-98.

15. Bai K, Fu Y, Liu C, et al. Pediatric non-diabetic ketoacidosis: a case-series report. BMC Pediatr 2017;17(1):209.

16. Owen OE, Caprio S, Reichard Jr. GA, et al. Ketosis of starvation: a revisit and new perspectives. Clin Endocrinol Metab 1983;12(2):359-79.

17. Higgins JP, Altman DG, Gotzsche PC, et al. The Cochrane Collaboration's tool for assessing risk of bias in randomised trials. BM7 2011;343:d5928.

18. Levy JA, Bachur RG, Monuteaux MC, Waltzman M. Intravenous dextrose for children with gastroenteritis and dehydration: a double-blind randomized controlled trial. Ann Emerg Med 2013;61(3):281-8.

19. Sendarrubias M, Carron M, Molina JC, et al. Clinical impact of rapid intravenous rehydration with dextrose serum in children with acute gastroenteritis. Pediatr Emerg Care 2018;34 (12):832-36.

20. Gorelick MH, Shaw KN, Murphy KO. Validity and reliability of clinical signs in the diagnosis of dehydration in children. Pediatrics 1997;99(5):E6.

21. Akech SO, Karisa J, Nakamya P, et al. Phase II trial of isotonic fluid resuscitation in Kenyan children with severe malnutrition and hypovolaemia. BMC Pediatr 2010;10:71.

22. Gutman RA, Drutz DJ, Whalen Jr GE, Watten RH. Double blind fluid therapy evaluation in pediatric cholera. Pediatrics 1969;44(6):922-31.

23. Juca CA, Rey LC, Martins CV. Comparison between normal saline and a polyelectrolyte solution for fluid resuscitation in severely dehydrated infants with acute diarrhoea. Ann Trop Paediatr 2005;25(4):253-60.

24. Mahalanabis D, Brayton JB, Mondal A, Pierce NF. The use of Ringer's lactate in the treatment of children with cholera and acute noncholera diarrhoea. Bull World Health Organ 1972;46(3):311-9.

25. Rahaman MM, Majid MA, Monsur KA. Evaluation of two intravenous rehydration solutions in cholera and non-cholera diarrhoea. Bull World Health Organ 1979;57(6):977-81.

26. Rahman O, Bennish ML, Alam AN, Salam MA. Rapid intravenous rehydration by means of a single polyelectrolyte solution with or without dextrose. F Pediatr 1988;113(4):654-60.

27. Tan PC, Norazilah MJ, Omar SZ. Dextrose saline compared with normal saline rehydration of hyperemesis gravidarum: a randomized controlled trial. Obstet Gynecol 2013;121 (2 Pt 1):291-8. 